\title{
UM MODELO PARA ORIENTAÇÃO FAMILIAL EM OLIGOFRENIAS
}

\author{
Aguinaldo Gonçalves :
}

Conceituam-se as oligofrenias como anormalidades orgânicas ou funcionais que levam a uma diminuição da função cognitiva, traduzindo-se por baixo quociente intelectual. No entanto, já a conceituação do que seja a normalidade em Medicina é algo muito operacional e pouco preciso. Poder-se-ia propor que a normalidade seja o perfeito equilíbrio biológico, sendo anormal tudo o que se lhe não enquadra. Entrementes, a importância deste desvio não guarda relação com sua extensão. Por exemplo, uma alteração grosseira na embriogênese dos membros superiores e inferiores, de que resulta sua fusão, a zigodactilia, é um desvio bastante grosseiro da mão normal, mas funcionalmente pode não constituir handicap na vida de correlação. Por outro lado, um pequeno estreitamento no canal de drenagem do líquido cefalorraquidiano determina hidrocéfalo, responsável por danos neurológicos de grande monta que podem levar inclusive à morte. Discussão análoga sobre o normal em biologia humana encontra-se em Alcântara (1970).

Revendo o problema da etiologia das oligofrenias, Zigler (1967) afirma que as duas últimas décadas testemunharam um interesse renovado pelo assunto, levando a numerosas pesquisas e publicações de teorias, que tentam uma explicação etiológica do evento.

Classicamente, a distribuição da inteligência comporta-se de acordo com uma curva normal, cujo caudal à direita à constituído pelos assim chamados deficientes mentais, formando uma classe homogênea, existindo, mesmo, numerosos ensaios que fazem comparações entre retardados e normais, sendo os dois grupos definidos unicamente a partir da determinação do quociente intelectual (Sellweger, 1963).

No entanto, uma distinção em dois subgrupos torna melhor manipulável o problema: existem os deficientes mentais fisiologicamente, por exemplo os afetados por encefalopatia bilirrubínica ou por sofrimento fetal. Adicionalmente, há os familiais, que compreendem $75 \%$ de todos os afetados.

Opondo-se a esta teoria ortodoxa da herança multifatorial da deficiência mental, Lehrke (1968), baseado em estudo de 105 oligofrênicos e 10 famílias, elaborou a chamada teoria dos traços intelectuais maiores ligados ao cromossomo $X$, que se apoia na aceitação de quatro hipóteses básicas, quais sejam: a) existem loci gênicos maiores relacionados ao funcionamento intelectual

* Médico geneticista do Conselho Nacional de Desenvolvimento Cientifico e Tecnológico. 
humano que estão localizados no cromossomo $\mathrm{X}$; b) tais genes, se mutados, podem levar a um funcionamento intelectual subnormal, incluindo retardo mental, transmitido como ligado ao cromossomo $\mathrm{X}$; c) um ou mais destes genes relacionam-se particularmente à função verbal; d) a deficiência relaciona-se primariamente ao sistema nervoso central.

Tal teoria, se verdadeira, poderia explicar muitas situações surpreendentes, incluindo o número substancialmente maior de homens retardados mentais e explicar, ao menos parcialmente, porque mais homens que mulheres estão em atividades que requerem niveis intelectuais mais elevados.

No entanto, mesmo que amplamente discutida pelo próprio autor em publicação ulterior (Lehrke, 1972), permanece tal teoria ainda sujeita a muitas críticas metodológicas (Anastasi, 1972; Nance e Engel, 1972).

Critérios globais de classificação etiopatológica das deficiências mentais têm sido difíceis de estabelecer. Constadinis (1963) as divide em exógenas e endógenas, sendo estas constituídas pelas de origem genética, seja unigênica (autossômicas e sexuais) ou poligênicas. Mais recentemente, Braga (1973), propõe divisão em funcionais e associadas a alterações orgânicas do sistema nervoso central, sendo esta categoria formada pelas ambientais (v.g. infecções, intercorrências gestacionais e partos traumatizantes); encefalopatias devidas a influências determinadas ( $p$. ex., doenças com comprometimento do sistema nervoso, sem uma etiologia precisa, v.g., esclerose cerebral difusa e degeneração cerebelar) e pelas doenças genéticas.

Desta aparente complexidade de causas envolvidas nas oligofrenias, emana a dificuldade que frequentemente encontram os clínicos para, frente a um caso de retardo mental, dar à família a conduta e orientação esperadas. Anteriormente, já se teceram considerações a respeito (Gonçalves, 1972). $\mathrm{Na}$ presente comunicação, complementarmente, apresenta-se um modelo operacional para a etiologia das oligofrenias, classificando-as em ambiental, gênica, cromossômica, familial e idiopática, a partir da apresentação de casos clínicos ilustrativos, oriundos do Ambulatório de Genética do Hospital das Clínicas da Faculdade de Ciências Médicas e Biológicas de Botucatu.

\section{CASUISTICA}

Caso 1 - G. A. L., sexo feminino, 5 anos de idade, brasileira (RG. 13409). Apresenta crises convulsivas há seis meses, com perda de consciência e liberaçāo esfincteriana, estando atualmente sob controle com anticonvulsivantes. Gradativamente, vem sendo notada deficiência mental, pela dificuldade na escolarização e relacionamento com as demais crianças. Não há dados relevantes quanto a antecedentes familiais e gestacionais. O parto foi demorado, o feto não progredindo espontaneamente, tendo havido, segundo a informante, "variação no foco". Ao exame físico, microcéfalo, hipertonia piramidal e assimetria facial, com paralisia à direita. Exames subsidiários clíntcos (sedimento urinário, protoparasitológico, hemograma, reação de Paul Bunnel e reação de Sabin-Feldman) negativos, assim como os genético-clínicos: não há alterações na análise dos dermatóglitos e cariótipo.

Caso 2 - O. L. S., branca, brasileira, 13 anos de idade, sexo feminino (RG. 30234). Boa evolução até cinco anos, quando se instalaram severa deficiência mental e visual, ficando. ao final de dois anos. completamente cega. Assim se 
manteve até há um ano, quando passou a apresentar crises convulsivas, sem aura, generalizadas, com liberação esfincteriana. Há uma semana, após uma destas crises, permanece torporosa, com quadro de agitação psicomotora; atualmente não anda e não controla esfincteres. Não há dados relevantes nos antecelentes gestacionais e peri-natais. Antecedentes familiais no heredograma 1 . Não há alteracões no exame físico. O exame neurológico revela apenas arreflexia tendinosa universal. Fundoscopia: atrofia papilar bilateral, pequenas áreas hiperpigmentares, assemelhando-se a retinose. Radiografia simples de crânio revela discreta hiperostose do vértex e das asas esfenóides; à pneumencefalografia, discreto aumento ventricular e cortical. A eletrencefalografia revela comprometimento difuso da eletrogênese, com irradiação para todas as áreas. Sem alteraçōes na análise dos dermatóglifos. Cariótipo não indicado.

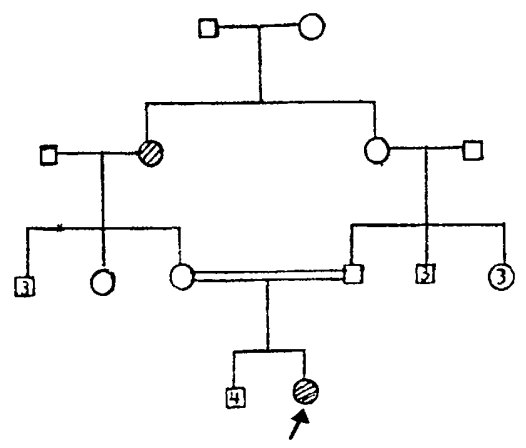

Fig. $I$ - Heredograma da familia de O. L. S., caso 2, mostrando caracteristicas compativeis de segregação autossômica recessiva.

CASO 3 - R. A. A., branco, sexo masculino, brasileiro, 12 anos de idade (RG. 13893). Encaminhado pela APAE para seguimento médico e conduta familial. Apresentou infecções repetidas de vias urinárias e desenvolvimento neuro-psico-motor retardado (tensão cervical no oitavo mês, primeiro dente com um ano, formação de frases com dois, controles esfincterianos com três), sendo, aos sete anos, encaminhado pelo pediatra para classe especial. Não há referências relevantes quanto a antecedentes familiais, gestacionais e peri-natais. Ao exame físico, hipotonia generalizada; achatamento occipital: estrabismo convergente à direita; cílios pequenos e esparsos; orelhas pequenas e de implantação baixa; nariz pequeno com ponte nasal baixa; hipoplasia de maxilar; pescoço curto e largo; pênis pequeno com criptorquia unilateral à direita. Nos exames subsidiários da anamnese genético-clinica, a análise dos dermatóglifos digito-palmares revelou braquidactilia universal, prega única e clinodactilia no quinto dedo, prega palmar do tipo $d$, bilateralmente; nas plantas dos pés, intervalo aumentado entre primeiro e segundo polidáctilo e sulco na primeira área interdigital, bilateralmente. A análise do cariótipo revelou, em sete células, trissomia de cromossomo do grupo 21-22.

Caso 4 - M. A. D., sexo masculino, branco, brasileiro, 9 anos de idade (RG. 16826). Apresentou desenvolvimento neuro-psico-motor retardado; rejeição social na primeira infância pelos colegas da mesma idade por ser lerdo e não executar as brincadeiras propostas pelo grupo. Há três anos está no primeiro ano da escola elementar, não tendo aprendido a ler, escrever ou contar. Não há dados relevantes nos antecedentes gestacionais e peri-natais, Antecedentes familiais apresentados no heredogrania 2. Não há alterações semiológicas de exame físico e exames subsidiários clínicos e genético-clínicos (dermatóglifos e cariótipo). 


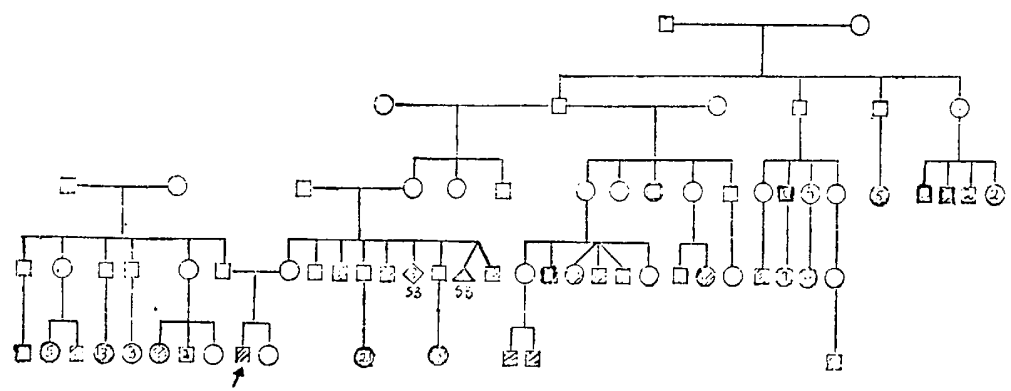

Fig. 2-Heredograma da familia de M. A. D., caso 4, revelando recorrência familial.

CASo 5 - S. M. R. A., sexo feminino, branca, brasileira, 2 anos de idade (RG. 31337). Encaminhada para Neuroclinica, porque a um retardo do desenvolvimento neuro-psico-motor (demorou para apresentar tensão cervical, ainda não fala, não anda e não tem controle esfincteriano) se soma "uma alteração nas linhas da mão" (sic). A anamnese e semiotécnica genético-clínica, não há alterações em antecedentes pessoais ou familiais; endocruzamento em ancestrais, incidência de malformações congênitas, recorrência do quadro atual; intercorrências gestacionais ou peri-natais. Exames subsidiários clínicos igualmente negativos (reação de imunofluorescência para toxoplasmose, Sabin-Feldman, teste do suor, reação de Wassermann, semiologia neurológica armada e fundoscopia). No cariótipo, não se observaram alterações em número ou morfologia em sete células analisadas. A análise dos dermatóglifos revelou, como única alteração, prega de Sidney unilateral à direita.

\section{DISCUSSAO}

Os casos apresentados, após a anamnese genético-clínica, revelaram oligofrenias, associadas ou não a retardo do desenvolvimento neuro-psico-motor, decorrentes de: caso 1 - etiopatogênese ambiental (hipóxia peri-natal por sofrimento fetal); caso 2 - etiopatogênese genética por doença gênica, autossômica recessiva (idiotia amaurótica, forma juvenil); caso 3 - etiopatogênese genética por doença cromossômica (mongolismo ou sindrome de Down); caso 4 - etiopatogênese familial; caso 5 - etiopatogênese idiopática.

Dado que a conceituação e discussão da etiopatogênese gênica e cromossômica, visando ao aconselhamento genético, se encontram em publicação recente (Gonçalves, 1974), serão objeto da presente as oligofrenias ambientais, familiais e idiopáticas, com vistas à orientação das famílias dos afetados.

A oligofrenia de etiopatogênese ambiental é a de mais fácil diagnóstico presuntivo. Já a anamnese pode revelar intercorrências gestacionais: ação de agentes teratogênicos, como nos casos de fenocópias (por exemplo, a síndrome talidomídica); infeçōes ou contactos infectantes, entre os quais rubela e toxoplasmose. Intercorrências neonatais e/ou peri-natais podem ser referidas (como no caso apresentado de sofrimento fetal), decorrentes de fatores maternos (v.g. má constituição de bacia), fetais (v.g. macrossomia, circular de cordão), materno-fetais (desproporção céfalo-pélvica) ou iatrogênicas (oxi- 
genação excessiva). A semiotécnica não revela sinais malformativos. As provas subsidiárias genético-clínicas são negativas, se indicadas. As oligofrenias por sequelas infecciosas revelam cicatriz sorológica na mãe e na criança. Quanto à conduta, o aconselhamento genético é favorável e desprezivel o risco de recorrência, desde que afastado o fator precipitante. Neste particular, é de importância óbvia o tratamento da eventual infecção materna.

Quando as informações colhidas na anamnese e semiologia genético-clínicas são do tipo observado em M.A.D. (caso 4), a recorrência intra-familial é o único dado positivo e seu comportamento geralmente não segue um padrão de herança típico e, se isto acontecer, este dado não deve ser supervalorizado, pois, a priori, está sujeito a muitos desvios. Por exemplo, por definição, a amostra é limitada a afetados e os não afetados via de regra não são examinados, mas considerados como tal pelo parente informante. Tendo em vista a variação nosográfica desta condição e seu decorrente pouco estudo, este grupo de deficientes "familiais" ou "culturais-familiais" compreende 75\% de todos os oligofrênicos. A conduta para tais afetados é ditada pela psicológa, após a realização de testes adequados de avaliação cognitiva do doente. No aconselhamento genético, além do significado potencial de que novos descendentes venham a ser afetados, mais probabilisticamente que a população em geral, a família deve ser esclarecida sobre o preponderante papel exercido pelo estímulo ambiente e pela cultura do grupo no desenvolvimento deste tipo de retardo mental.

O caso S.M.R.A. ilustra bem os chamados casos idiopáticos, designação do atual estágio da ignorância médica a respeito. Não há alterações laboratoriais especificas (que definam uma oligofrenia ambiental), conjunto de pequenos sinais malformativos (no caso, apenas uma prega palmar variante) ou antecedentes familiais (que indiquem a possibilidade de uma síndrome genética), nem recorrência familial da conđição (situação característica da oligofrenia familial). Permanecem, assim, tais casos como diagnóstico de exclusão, à espera de melhores recursos técnicos e definições nosográficas mais elaboradas. A terapêutica é sintomática, fisioterápica e ocupacional e o aconselhamento genético, com base nos riscos empíricos.

Destarte, diante de um oligofrênico, deve o clínico, pediatra ou psiquiatra, orientar o diagnóstico sindrômico no sentido de uma das cinco etiopatogêneses apresentadas, tendo, assim, condições para a respectiva conduta familial. Quando houver superposição de quadros, para o aconselhamento genético, deve ele compor a probabilidade acumulada. Por exemplo, a mãe de um deficiente mental com antecedentes familiais positivos refere toxoplasmose durante a gestação. Além das condutas especificas sugeridas pelas duas situações, é necessário acrescentar ao risco de recorrência pela afecção familial, o risco que mães de oligofrênicos por toxoplasmose têm de o próximo filho ser igualmente deficiente mental. Em casos de dúvida ou consulta, os Sereviços de Genética Médica podem, se necessário, apresentar pronta assessoria. 


\section{RESUMO}

Após revisão de teorias e evidências sobre a etiologia das oligofrenias, são apresentados casos clínicos de oligofrênicos atendidos em serviço de Genética Médica, os quais servem de substrato para a proposição de um modelo de Aconselhamento Genético, que os classifica em ambiental, gênica, cromossômica, familial e idiopática.

\section{SUMMARY}

\section{A model for familial orientation on mental retardation}

Theories and evidences on etiology of mental retardation are presented. Five cases of mental retardation from a Clinical Genetics Service are reported, as basis for an etiological model on mental retardation, quite operational in genetic counseling and familial orientation.

\section{REFERENCIAS}

1. AlCÂNTARA, P. - A criança normal, essa desconhecida. In AlCânTARA, P. - Pediatria Básica 1:3. Sarvier Editora, São Paulo, 1970.

2. ANASTASI, A. - Four hypotheses with a dearth of data: response to Lehrke's "a theory of X-linkage of major intellectual traits". Am. J. Men. Def. 76: 620,1972 .

3. BRAGA. J. C. - Retardamento mental: aspectos etiológicos. Ped. Mod. (São Paulo) 7:50, 1973 .

4. CONSTANTIDiNis, J. - Les oligophrenies endogenes. J. Gen. Hum. 1:55. 1963.

5. GONÇALVES, A. - Estudo genético das oligofrenias: revisão dos casos do Ambulatório de Genética. Anais II Jorn. Cient. Fac. Cienc. Méd. Biol. Botucatu 35, 1972 .

6. GONÇALVES, A. - Ambulatório de Genética II: os diferentes elementos das patologias atendidas. Rev. Bras. Clin. Terap. 3:37, 1974.

7. LEHRKE, R. - A theory of X-linkage of major intellectual traits. Am. J. Ment. Def. 76:711, 1972 .

8. NANCE, W. E. \& ENGEL, E. E. - One $\mathrm{X}$ and four hypothesis: response to Lehrke's "a theory of X-linkage of major intellectual traits". Am. J. Ment. Def. $76: 623,1972$.

9. ZELLWEGER, H. - Genetic aspects of mental retardation. Arch. Int. Med. $111: 165,1963$.

10. ZIGLER, E. - Familial mental retardation: a continuing dilemma. Science $155: 292,1967$.

Laboratório de Genética Médica - Faculdade de Medicina, Universidade de Sĩo Paulo - Caixa Postal 2.921 - 01000 Sĩo Paulo. SP - Brasil. 